\title{
Assessment of the factors of mental health of the elderly population of Russia on the basis of individual data
}

\author{
Anna M. Kashcheeva ${ }^{1}$ \\ 1 PJSC Sberbank, Moscow 117997 Russia
}

Received 1 July 2019 • Accepted 12 September 2019 • Published 30 September 2019

Citation: Kashcheeva AM (2019) Assessment of the factors of mental health of the elderly population of Russia on the basis of individual data. Population and Economics 3(3): 117-140. https://doi.org/10.3897/popecon.3.e47190

\begin{abstract}
Mental health is determined as a state of well-being in which the individual realizes his or her own abilities, can cope with the normal stresses of life, can work productively and fruitfully, and is able to make a contribution to his or her community (WHO 2014, 2017). By taking the example of the elderly population of Russia the article reveals the existence and nature of ties between individual socio-economic characteristics of the older age people and the level of their mental health. The article presents the author's method of assessment of mental health of the elderly population, which is based on a brief scale of the Center for Epidemiologic Studies Depression Scale (CES-D). Individual data from the WHO International Study of Global Ageing and Adult Health (SAGE) conducted in the regions of Russia in 2002-2004 (wave 0) and in 2007-2010 (wave 1) are used as the empirical basis of the study.
\end{abstract}

\section{Keywords}

mental health and well-being, the elderly population, the principal components analysis

JEL Codes: C10, J10, J14

\section{Introduction}

Mental health is not merely the absence of disease (WHO 2004). Initially, mental health was seen as a condition of a person with a complete absence of mental illness (Sigerist 1941; WHO 1948). The incompleteness and limitations of this definition were overcome relatively recently, in 2004, when WHO defined mental health as a state of well-being in which the individual realizes his or her abilities, can cope with the normal stresses of life, can work pro- 
ductively and fruitfully, be result-oriented, and contribute to his or her community (WHO 2004, 2017).

Scientific interest in the study of mental health increased significantly following the publication of the work of WHO researchers on measuring the burden of various diseases, including mental illness (Murray and Lopez 1996). The study shows that by the end of the 20th century the burden of mental disorders is not inferior to the burden of circulatory diseases and malignant neoplasms: depression was ranked the fourth among most important factors limiting the activities of the individual.

In Russia, studies of the influence of socio-economic characteristics on the level of mental health and well-being of the population have also begun to be actively carried out since the end of the 20th century. One of the first works in this field is the article of B. Kennedy and co-authors dedicated to the impact of social capital on the mortality rate of the Russian population (Kennedy et al. 1998). Researchers have shown a positive relationship between social capital and life expectancy, as well as a decrease in the overall mortality rate with rising social capital indicators. Special attention was paid to informal sources of social support the closest environment of the individual: family and friends. Social cohesion of society was measured by the level of crime and presence of conflicts in the workplace of the individual, according to the polls of the Russian Public Opinion Research Center (VICOM). In a later article (Rose 2000), based on individual level data on physical and emotional health it was found that social capital and human capital have a significant impact on both physical and mental health. That research was based on individual characteristics of the assessment of the physical and emotional health obtained through the 1998 New Russia Barometer Survey. Social capital components that have a significant impact on mental health include: involvement in formal or informal networks and communities, presence of friends on which one can rely in the event of illness, control over one's own life, and confidence.

Research on mental health of the elderly population of Russia is mostly based on data from the cohort study of the urban population in Eastern Europe - "Health, Alcohol and Psychosocial factors In Eastern Europe (HAPIEE)”, including Russia ( Novosibirsk), Poland (Krakow), Czech Republic ( Havírov, Hradec Králové, Jihlava, Kroměříž, Liberec, Ústí nad Labem). The survey has a number of significant limitations: namely, a sample of respondents from Russia (476 men and 467 women) represents the population of only one city. Nevertheless, this is the first study to make a cross-country comparison and it is the first use of the scale of the Centre for Epidemiologic Studies Depression Scale (CES-D) in Russia. The papers based on this survey present a negative relationship between mental health and loneliness, excessive alcohol consumption and low income (Bobak et al. 2006). There is also a differentiation by sex: in Eastern Europe, all other things being equal, women are more vulnerable to depression than men; however, the differences are blurred in more educated groups. The greatest gender differentiation of the risk of depression is observed in Russia (Nicholson et al. 2008).

The issues of mental well-being were examined on the example of the health of children and adolescents (Charman and Pervova 1996; Jose et al. 1998), as part of a survey based on methodologies for diagnosing mood disorders in children and adolescents, Child Depression Inventory (CDI) and Depression Self-Rating Scale (DSRS), as well as author's methods followed by analysis of the obtained indicators characterizing mental health of Russian and American children and adolescents. Regional analysis of socio-economic characteristics and mental health is partially presented in the work on the Republic of Udmurtia (Pakriev et al. 1998), mental health was measured via the interview method - Composite International Diagnostic Interview (CIDI), as well as in a similar study of the city of Arkhangelsk (Ave- 
rina et al. 2005), in which the methodology for measuring mental health was taken from a similar study for Norway (Westlund and Søgaard 1993; Nilssen et al. 1999). All studies show a positive relationship between mental health and high socio-economic status of the respondent, as well as a negative relationship with excessive alcohol consumption.

The results of the cohort study Stress Aging and Health in Russia (SAHR) conducted between December 2006 and June 2009, which includes a wide range of characteristics of Moscow's population (men and women over 55 years of age) in terms of health, socio-economic and demographic characteristics, cognitive abilities, exposure to stress/depression, as well as various biomarkers showed a high gap in life expectancy between men and women. It gave ground to suggest a negative relationship between stress accumulation and life expectancy (Shkolnikova et al. 2009; Oksuzyan et al. 2015).

Among the consequences of mental health disorders, mortality due to suicide among elderly people is to be emphasized. In Russia, the old-age people are regarded as a group with increased suicidal risk (Danilova 2014; Vishnevsky 2017). An important area of study is gerontopsychology and research of gerontologists. The first study of the attitude of elderly patients to depression and its treatment in Russia is presented in the work on the city of St. Petersburg (Jogerst et al. 2010). The study revealed a positive attitude to the treatment of depression, as well as the relationship of depressive disorders with income and excessive alcohol consumption.

Some works by Western and Russian authors are dealing with assessing the socio-economic burden of mental and behavioural disorders such as schizophrenia (Weiden and Olfson 1995; Lyubov and Yastrebov 2012), Alzheimer's disease (Fox et al. 2001), dementia (Wubker et al. 2015) and the class of mental and behavioral disorders in general (Gurovich et al. 2010; Yastrebov et al. 2014), as well as analysis of the effectiveness (benefit and cost analysis) of various measures to provide care for people with mental disabilities (Hoch et al. 2002), analysis of direct and indirect costs in the treatment of mental disorders (Oliva-Moreno et al. 2009), analysis of the impact of negative economic shocks on mental health (Urbanos-Garrido and Lopez-Valcarcel 2015).

The combination of modern methods of statistical and demographic analysis is presented in the work of German researchers (Raab et al. 2018) who use cluster analysis to separate the general sample by subgroups on physical and mental health.

Despite the fact that the issues of mental health and well-being of the elderly population of Russia are currently attracting more and more attention of researchers, there are few studies which offer assessments of the factors of mental health of the elderly population. That's why this paper is focused on the relationship between the socio-economic characteristics of the elderly people of Russia and their mental health.

\section{Definition of mental health}

Historically, there are two approaches to the definition of mental health: hedonic and eudemonic, which were later added by the concept of social well-being, making it possible to present so-called "triangular models", which reflect all of the contemporary aspects of mental health (see Table 1).

According to the hedonic tradition, the key components of mental health and well-being include: a high level of positive emotions and level of satisfaction with life, as well as a low level of negative emotions and experiences. A significant contribution to the development of the hedonic approach was made by N.M.Bradburn (Bradburn 1969), G. Gurin, J.Veroff, S.Feld (Gurin et al. 1960), E. Diener (Diener 1984, 1985) et al. 
Table 1. Approaches to the definition of mental health.

\begin{tabular}{|c|c|}
\hline \multirow{2}{*}{$\begin{array}{l}\text { The hedonic approach } \\
\text { (emotional well-being) }\end{array}$} & Positive emotions, interest in life, happiness \\
\hline & Judgment on the quality of life (in general and in certain areas) \\
\hline \multirow{6}{*}{$\begin{array}{l}\text { The eudemonic ap- } \\
\text { proach (psychological } \\
\text { well-being) }\end{array}$} & Accepting yourself as a person \\
\hline & Personal growth, self-development \\
\hline & Goal-setting, sense of own importance, determination of life directions \\
\hline & Social responsibility, decision-making \\
\hline & $\begin{array}{l}\text { Autonomy, confidence in the expression of own ideas, opinions and } \\
\text { values }\end{array}$ \\
\hline & Positive relations with others, high level of trust \\
\hline \multirow{4}{*}{$\begin{array}{l}\text { Social well-being Keyes } \\
\text { (1998) }\end{array}$} & Positive attitude towards others \\
\hline & $\begin{array}{l}\text { Social growth, activities aimed at the development of society and the } \\
\text { environment Social inclusion }\end{array}$ \\
\hline & A sense of unity, cohesion of society \\
\hline & A sense of belonging to society, a sense of social support \\
\hline
\end{tabular}

Source: compiled by the author.

According to the hedonic approach mental health includes positive emotions, satisfaction with life, and happiness, and therefore, corresponds to the concept of emotional wellbeing. One of the most significant models in the framework of this approach is the model that reflects the relationship between life satisfaction and positive and negative external influence. This model highlights the factors that affect the well-being of the individual: factors that have a positive impact, factors that have a negative impact, and overall level of life satisfaction. The author attributed the first two factors to emotional evaluation and the latter to cognitive judgment (Diener et al. 1985).

In the works that define mental health through the concept of hedonic approach, researchers mainly rely on scales of individual questionnaires such as the Positive and Negative Affect Schedule (PANAS) (Watson et al. 1988) and The Subjective Happiness Scale (SHS) (Lyubomirsky and Lepper 1999).

According to the eudemonic tradition, the main signs of mental health are: a sense of self-worth, self-confidence, development and implementation of one's own potential, active goal-setting, interaction with the environment, a high level of trust - all this allows to define this concept as a concept of psychological well-being. A great contribution to the development of this direction was made by C. L. Keyes (1998), C. D. Ryff (1989) and others.

In order to measure the mental health indicator, the studies based on the eudemonic approach often uses the scale of one of the founders of this approach, the Ryff's scale (1989).

Within the frames of the eudemonic approach to mental health, the concept of social well-being is developed (Keyes 1998). According to this concept, mental health depends on a person's attitude towards others, his/her position in society and the perception of society as a whole. A scale of 34 questions was proposed for measurement (Keyes 1998).

Three approaches to the definition of mental health provide an opportunity to make a many-sided analysis of the key aspects of mental health: emotional problems resulting from dissatisfaction with life; problems of contacting with the society and living in the society; problems of the absence of life aims and interest to life. 
The purpose of this paper is to combine the existing approaches to understanding the mental health and assess the relationship between mental health and socio-economic characteristics of the elderly population.

\section{Data}

This paper uses data of the longitudinal international study of the elderly population, Study on Global Ageing and Adult Health (SAGE), conducted by WHO in Russia in 2002-2004 (wave 0) and 2007-2010 (wave 1). Subsequent waves of study: 2014-2015 (wave 2) and 2017 (wave 3) for Russia are combined into one and are currently unavailable.

Wave 0 . A complete sample of individual data includes 4,422 respondents aged between 18 and 100 years.

Wave 1. A complete sample of individual data includes 436 respondents aged 18 to 49 and 4,511 respondents aged 50 to 100 years.

The initial cohort of respondents participating in the SAGE study was formed during the first wave in 2002-2004, however, every subsequent wave was supplemented by new participants in the survey. The sample is representative over the country.

Both individual and household data were used to build the model. Both datasets were compared by the assigned household ID field. For modeling, there were selected complete interviews with the population of retirement age, i.e. responses from men over 60 years and women over 55 years who participated in both the first and the in the second wave of research.

In both waves both urban and rural inhabitants of regions of Russia were interviewed. The questionnaires are voluminous and cover many important aspects of life: social and economic characteristics of the respondent, employment, health status, health services, exposure to risks (including alcohol and tobacco consumption), issues regarding the respondent's lifestyle. The second wave, unlike the first, also contains the results of various tests (verbal, mathematical, vision, etc.), questions about the presence of chronic diseases, as well as social connections and satisfaction with the standard of living. The geographical coverage of respondents is wide enough to justify the representativeness of the sample used: at the time of the survey, the respondents lived in Moscow, Nizhny Novgorod, Tver, Yaroslavl, St. Petersburg, Lipetsk, Chelyabinsk, Omsk, Volgograd, Krasnodar, etc.

The disadvantage of individual questionnaires data is the subjectivity of the respondents' answers, on the basis of which estimates of physical health, satisfaction with life, etc. are made. In addition, when completing the questionnaire, respondents from different countries and social groups may have different understanding of well-being, satisfaction, trust, etc. (Bertrand and Sendhil 2001).

The global trend of population ageing means that the elderly population is becoming more important and more significant in the age structure of society. Interest in the study of the elderly population is also based on the fact that in old age there are various significant life events - sharp decline in income, loss of spouse, worsening level of physical health, reduction of social contacts, etc., which distinguishes this age group from the younger population (Lindeboom et al. 2002).

\section{Methods}

When including different characteristics of the social, cultural, economic and other aspects of the life of the individual in the indicator of mental health and well-being, scientists note 
the dependence of this indicator on characteristics of the sample being studied. These differences highlight the difficulty of comparing different groups of population in terms of mental health and well-being (Roberts et al. 1997).

Thus, the methods used in the analysis of mental health and well-being often depend on the economic, social and cultural characteristics of a particular region, and therefore, present a subjective assessment of mental health and well-being of the population (Diener et al. 1999). Such an assessment makes cross-country comparisons difficult, as mental health and well-being can also be influenced by hidden, unobserved characteristics that affect the quality of long-term monitoring of individual mental health.

In this paper, the index of assessment of the mental health of elderly people on the basis of individual data is proposed.

In order to choose the strategy of building the mental health index, methods most commonly used in scientific research were considered:

- WHO (Five) Well-Being Index - the method was first presented in 1998 in Stockholm by the WHO Regional Office for Europe as part of the DEPCARE project on welfare measures in primary healthcare. During the period of use of the methodology, both clinical and psychometric validity were confirmed in a number of studies. The index is based on 5 questions, the answers to which are measured on a scale from 0 to 5 , where 0 is "never", 5 is "always".

- The Center for Epidemiologic Studies Depression Scale. The Center was established in 1977 (Radloff 1977) and its main task is to measure a large depressive episode, the evaluation methodology of which was first used in mental health evaluation surveys in the 1970s and in national health and nutrition surveys. The index is based on 20 questions relying on the state over the past week; the answers are evaluated on a scale from 0 to 3 (4) depending on the category of the question.

- The Depression Anxiety Stress Scale focuses on three characteristics, mainly determining the mental health of the individual: depression, anxiety and stress. The index was developed by the researchers from the University of New South Wales (Australia) (Lovibond and Lovibond 1995) and is an estimate of 42 symptoms on a scale of 1 to 4 . The authors emphasize that the test can be used exclusively for educational purposes, while for clinical diagnosis it is necessary to refer to other tools.

- The Short Depression-Happiness Scale (SDHS) (Joseph et al. 2006) is a short version of the basic scale of "depression/happiness"; it consists of 6 questions (the full version contains 25), reflecting three positive and three negative states, respectively, to assess over the past two weeks. The index passed empirical testing on a sample of respondents from the USA and the UK, which confirmed the reliability of its use to reflect the mental health of the population.

- The Warwick-Edinburgh Mental Well-being Scale (WEMWBS). The methodology was developed by researchers from the universities of Warwick and Edinburgh, funded by the Scottish National Health System to measure adult mental well-being in the United Kingdom. The index is based on 14 questions, the answers to which are evaluated on a scale of 1 to 5 .

- The General Health Questionnaire (GHQ-12) is a measurement of psychological well-being. This technique is suitable for all ages. The questions are focused on determining whether there is an inability to manage daily affairs and the occurrence of a previously unencountered disturbed state. The questionnaire is presented in four variants consisting of $60,30,28$ or 12 questions respectively. 
In addition to the above-mentioned methods of assessing mental health, others were considered - the Montgomery-Asberg Depression Scale, Hamilton Scale, SF-36, Positive and Negative Affect Scale, Satisfaction With Life Scale, Global Life Satisfaction Scale, Scale of Psychological Well-being, EQ-5D Thermometer, Emotional Intelligence Scale, etc. However, all the indices presented have a high correlation (Stewart-Brown et al. 2007), which enables concentrating on the most relevant and applicable SAGE to the WHO study.

The Geriatric Depression Scale (GDS-15) was developed directly for self-assessment of the mental health of the elderly population. The scale is one of a few universally accepted scales used in working with the elderly population.

The limitations of existing methods of assessment of mental health and well-being of the elderly population as a separate group give reasons for development of the author's method of estimation of this indicator.

Based on the results of earlier studies, we analyze the relationship between mental health and the following groups of individual characteristics of the elderly population of Russia:

- demographic characteristics (sex, age, marital status) and state of health characteristics (level of physical health);

- social characteristics (education, intra-group and interpersonal trust, presence of a close relative in need of support (including emotional);

- economic characteristics (is the available money enough for everyday needs?).

On the basis of the analysis of scientific literature, for the studied sample of the elderly population of Russia (men and women of pension ages) the following hypotheses were formulated:

$\mathbf{H}_{1}$ Hypothesis. Other things being equal, women in Russia on average are more susceptible to mental health deterioration than men.

$\mathbf{H}_{2}$ Hypothesis. Other things being equal, the loss of a spouse is negatively related to the mental health of the respondent.

$\mathbf{H}_{3}$ Hypothesis Other things being equal, having a higher education is positively related to the state of mental health.

$\mathbf{H}_{4}$ Hypothesis. Other things being equal, the level of both intra-group and interpersonal trust is positively related to the state of mental health of the respondent.

The CES-D-10 methodology is the basis for comparative analysis and adaptation of WHO SAGE data. The choice of this methodology is justified by the following provisions:

1. Compared to the traditional CESD-20 method, CESD-10's short version excludes issues related to somatic disorders, which are often the result of the natural ageing process of the body. (Ivanets et al. 2016).

2. The Scales of the Center for Epidemiological Studies (CES-D-20, CES-D-10) are the most commonly used tool for measuring mental health and well-being in authoritative scientific publications selected in accordance with the requirements for the scientific publications used in this work.

3. The paper introduces a premise about the possibility of application of the international methods for measuring mental health and well-being to the analysis of mental health of the elderly population of Russia.

\section{Adaptation of CESD-10 survey questions to WHO SAGE research questions}

The adaptation of CESD-10 survey questions to the WHO SAGE wave 1 survey (2007-2010) was to select similar questions to comply with a key set of categories and relevant indicators, which are part of the indicator of mental health and well-being (see Table 2). 
Table 2. Comparison of CESD-10 questions and WHO SAGE questions, wave 1 (2007-2010).

CESD-10

WHO SAGE, wave 1

\begin{tabular}{|c|c|c|}
\hline 1 & $\begin{array}{l}\text { I was bothered by things that usually } \\
\text { don't bother me }\end{array}$ & no analogue \\
\hline 2 & $\begin{array}{l}\text { I had trouble keeping my mind on what I was } \\
\text { doing }\end{array}$ & $\begin{array}{l}\text { Difficulties in daily household activities } \\
\text { (Q2001) }\end{array}$ \\
\hline 3 & I felt depressed & Feeling sad, low or depressed (Q2018) \\
\hline 4 & I felt that everything I did was an effort & $\begin{array}{l}\text { Not feeling rested or refreshed during the day } \\
\text { (Q2017) }\end{array}$ \\
\hline 5 & I felt hopeful about the future & no analogue \\
\hline 6 & It seems to me that my life has failed & $\begin{array}{l}\text { Assessments of satisfaction with the state of } \\
\text { health, oneself, life, relationships with other } \\
\text { people, living conditions } \\
\text { (Q7003-Q7007) }\end{array}$ \\
\hline 7 & I feel fearful & Presence of worry and anxiety (Q2019) \\
\hline 8 & My sleep was restless & Presence of sleep disorders (Q2016) \\
\hline 9 & I was happy & Do you feel happy/unhappy (Q7010) \\
\hline 10 & I felt lonely & no analogue \\
\hline
\end{tabular}

Source: compiled by the author on the basis of CESD-10, WHO SAGE-2007/10 (wave 1).

Most CESD-10 questions (seven out of ten) managed to find analogs in the WHO SAGE study. A complete match of the wording was found for four questions of the CESD-10 questionnaire: "I feel depressed", "I feel fearfull", "I have a bad night's sleep", "I feel happy”.

The following assumptions were introduced for the three questions:

- "I had trouble keeping my mind on what I was doing"- it is assumed that the individual faces some difficulties in doing daily household tasks because the wording of the issue is more of routine work than of achievement of any goals;

- "I felt that everything I did was an effort" - assumes the dependence of the result of work, achievement of goals, etc., not only on the existing individual competencies and skills, but also on additional costs (including physical, temporary, etc.), therefore, we will introduce the premise of fatigue, loss of energy by the respondent;

- "It seems to me that my life has failed" - for this question we will use indicators of satisfaction with different areas of life: oneself, relationships with others, living conditions and life in general, trying to reflect to a maximum extent the individual attitude and the degree of satisfaction with life.

For the following questions, no analogues were found in the WHO SAGE study:

- "I was bothered by things that usually don't bother me ";

- "I felt hopeful about the future";

- "I felt lonely"

Thus, the indicator of mental health and well-being of the elderly population of Russia used in this work includes responses to eleven questions from the WHO study (see Table 2).

The answers to the questions do not require standardization, as they are measured in a single five-point scale system (see Table 3 ). 
Descriptive statistics of indicators are presented in Table 4.

Currently, the following methods are used to construct indicators of mental health:

The Summarized indicator - the most commonly used method for generating an indicator of mental health and well-being of a respondent based on surveys.

Table 3. Survey questions used in constructing an indicator of mental health.

\begin{tabular}{|c|c|c|}
\hline & Survey question & Measurement scale \\
\hline Q2001 & $\begin{array}{l}\text { Difficulties in managing daily household } \\
\text { activities (Disability) }\end{array}$ & \multirow{5}{*}{$\begin{array}{l}1 \text { - no (difficulties, disorders...) } \\
2 \text { - minor ((difficulties, disorders...) } \\
3 \text { - average (difficulties, disorders...) } \\
4 \text { - considerable (difficulties, disorders...) } \\
5 \text { - extreme difficulties, (very severe } \\
\text { disorders) }\end{array}$} \\
\hline Q2016 & Presence of sleep disorders (Insomnia) & \\
\hline Q2017 & Fatigue, energy loss (Fatigue) & \\
\hline Q2018 & $\begin{array}{l}\text { The presence of sad, depressive states, feel- } \\
\text { ings of devastation (Depression) }\end{array}$ & \\
\hline Q2019 & Presence worry and anxiety (Anxiety) & \\
\hline $\begin{array}{l}\text { Q7003 - } \\
\text { Q7007 }\end{array}$ & $\begin{array}{l}\text { Assessments of satisfaction with Health, } \\
\text { Yourself, Life, Relationships, living Con- } \\
\text { ditions }\end{array}$ & $\begin{array}{l}1-\text { very much satisfied } \\
2-\text { satisfied } \\
3-\text { not clear } \\
4-\text { not satisfied } \\
5-\text { not satisfied at all }\end{array}$ \\
\hline Q7010 & Do you feel happy/unhappy (Happiness) & $\begin{array}{l}1 \text { - very happy } \\
2-\text { happy } \\
3-\text { not clear } \\
4-\text { unhappy } \\
5 \text { - very unhappy }\end{array}$ \\
\hline
\end{tabular}

Source: WHO SAGE-2007/10 (wave 1).

Table 4. Descriptive statistics of indicators used.

\begin{tabular}{|c|c|c|c|c|}
\hline Variable & Mean & Median & Min & Max \\
\hline Disability & 2.66 & 3 & 1 & 5 \\
\hline Insomnia & 2.35 & 2 & 1 & 5 \\
\hline Fatigue & 2.32 & 2 & 1 & 5 \\
\hline Depression & 1.68 & 1 & 1 & 5 \\
\hline Anxiety & 1.81 & 2 & 1 & 5 \\
\hline Health & 3.06 & 3 & 1 & 5 \\
\hline Yourself & 2.51 & 2 & 1 & 5 \\
\hline Relationships & 2.17 & 2 & 1 & 5 \\
\hline Conditions & 2.34 & 2 & 1 & 5 \\
\hline Happiness & 2.72 & 3 & 1 & 5 \\
\hline Life & 2.58 & 2 & 1 & 5 \\
\hline
\end{tabular}

Source: author's calculations. 


$$
\text { Mental__Health }{ }_{i}=\sum_{i=1}^{11} Q_{i}
$$

For example, the summarized indicator is used in the formation of the indicator of mental health and well-being according to the WHO-Five Well-being Index questionnaire, CES-D-20, CES-D-10.

Arithmetical mean is less common, but is also a popular measure of mental health and well-being of the surveyed:

$$
\text { Mental__Health }{ }_{i}=\frac{\sum_{i=1}^{11} Q_{i}}{11}
$$

For example, the arithmetic mean indicator is used to generate mental health and wellbeing indicators from The Short Depression-Happiness Scale (SDHS).

The indicator developed and used in this work is based on the Principal components analysis (PCA). PCA was chosen for the following objective reasons of use:

1. The mental health indicator requires indirect evaluation, taking into account the variance of the indicators used;

2. It is assumed that the answers of the eleven selected questions can be strongly correlated among themselves.

The principal components analysis enables forming new features, which are linear combinations of old ones, and at the same time retain the maximum amount of information contained in the original features. The linear combination is designed to maintain the maximum variance in the data, optimally reducing data dimension, thus decreasing the risk of

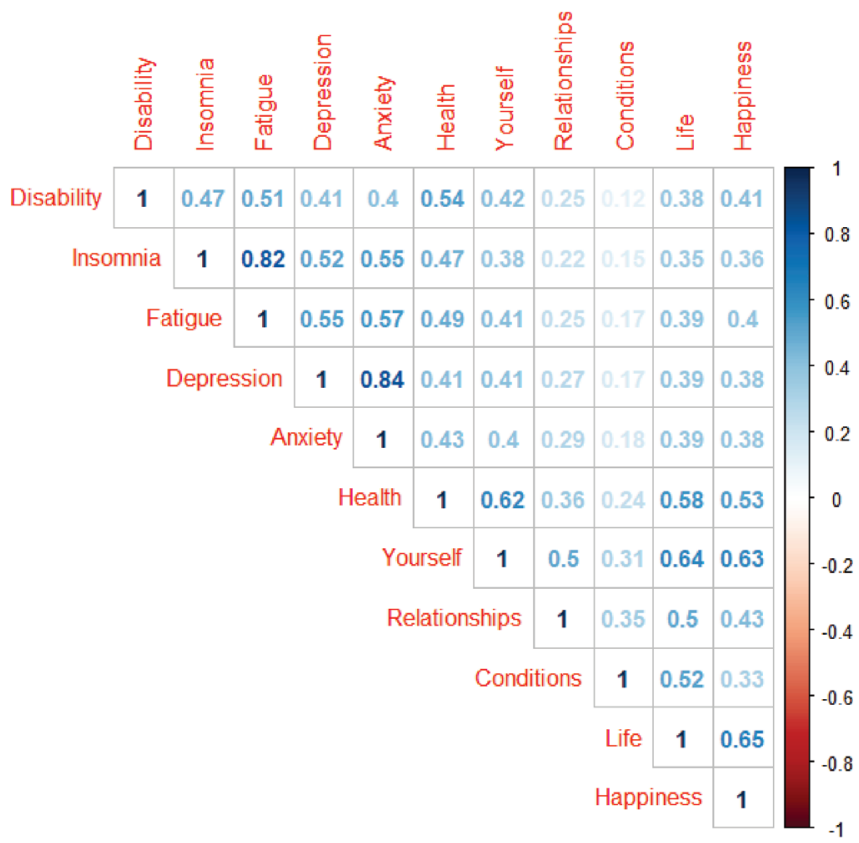

Figure 1. Correlation matrix of mental health indicators. Source: author's calculations. 
multicollinearity, preserving the possibility of convenient interpretation of the obtained results.

To start, it is necessary to characterize the dependence of certain features by means of correlation analysis (see Figure 1). The correlation matrix of indicators in the definition of mental health demonstrates high correlation of answers to questions on the presence of sleep disorders and feeling of fatigue (the correlation of these indicators is 0.82 ); satisfaction of life and feeling of happiness (0.65), and satisfaction with one self (0.64). The least correlation is the answers to questions on satisfaction with living conditions and difficulties in daily activities (0.12), sleep disorders (0.15), fatigue ( 0.17 ) and depression (0.17). Also note that all considered indicators are positively correlated among themselves.

The number of principal components corresponds to the number of indicators used. Let's build 11 principal components (K1,... K11) (see Table 5).

Figure 2 demonstrates graphical display of the calculated principal components.

Table 5. Principal components.

\begin{tabular}{lccccccccccc}
\hline & K1 & K2 & K3 & K4 & K5 & K6 & K7 & K8 & K9 & K10 & K11 \\
\hline Standard deviation & 2.13 & 1.11 & 0.90 & 0.81 & 0.70 & 0.61 & 0.56 & 0.48 & 0.44 & 0.43 & 0.38 \\
\hline $\begin{array}{l}\text { Proportion of the } \\
\text { variance explained }\end{array}$ & 0.49 & 0.13 & 0.09 & 0.07 & 0.05 & 0.04 & 0.03 & 0.03 & 0.02 & 0.02 & 0.02 \\
\hline $\begin{array}{l}\text { Cumulative fraction } \\
\text { of variance } \\
\text { explained }\end{array}$ & 0.49 & 0.63 & 0.72 & 0.79 & 0.84 & 0.88 & 0.92 & 0.94 & 0.96 & 0.98 & 1.00 \\
\hline
\end{tabular}

Source: author's calculations.

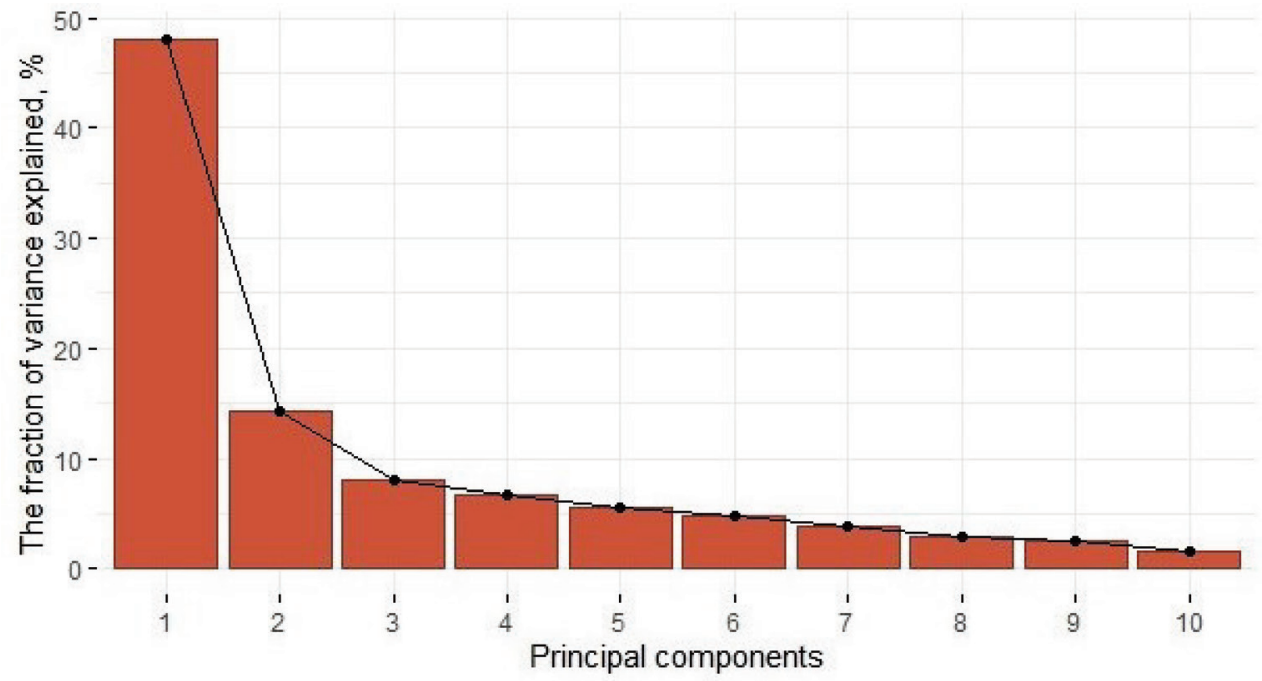

Figure 2. Principal components. Source: author's calculations. 
The first principal component explains $49 \%$ of the variance, the proportion of the explained variance by the other main components can be considered insignificant. In the empirical study, we will use the results obtained for the first principle component.

Figure 3 shows the characteristic vectors of the initial two principal components by using the intensity colour scale, which shows the direction and significance of the contribution of certain indicators.

To assess the contribution of each indicator, we take the calculated value of the first principal component for the individual level of mental health and well-being of the elderly person.

The characteristic vector of the first principal component is represented in the Table 6 . The lowest contribution is reflected by the indicator characterizing satisfaction with living

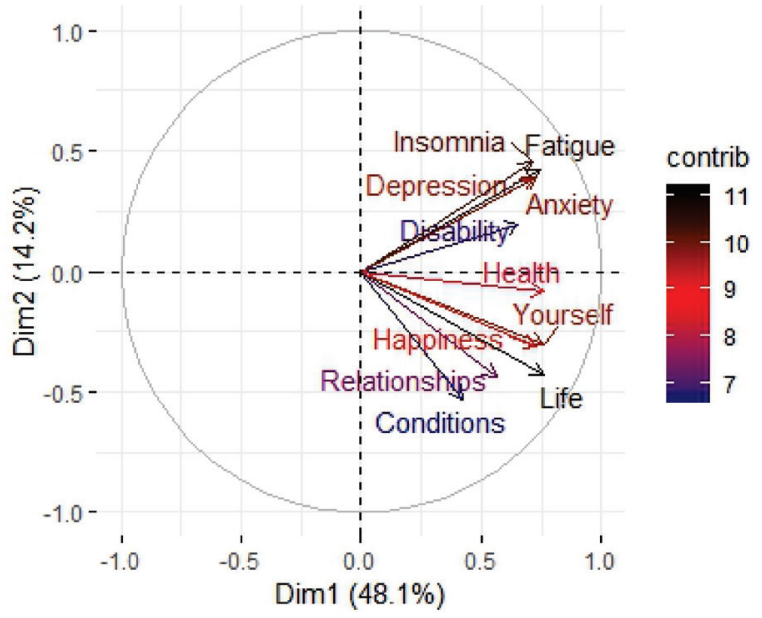

Figure 3. Contribution of indicators to the initial two principal components. Source: author's calculations.

Table 6. Contribution of indicators to the first main component (K1).

\begin{tabular}{clc}
\hline Indicator & \multicolumn{1}{c}{ Interpretation } & Weight \\
\hline Yourself & Satisfaction with yourself & 0.3303 \\
\hline Health & Satisfaction with state of health & 0.3303 \\
\hline Life & Life satisfaction & 0.3297 \\
\hline Fatigue & Fatigue, energy loss & 0.3243 \\
\hline Happiness & Happiness & 0.3173 \\
\hline Anxiety & Presence of worry and anxiety (Q2019) & 0.3160 \\
\hline Depression & Feeling sad, low and depressed (Q2018) & 0.3119 \\
\hline Insomnia & Presence of sleep disorders & 0.3088 \\
\hline Disability & Presence of difficulties in daily household activities & 0.2846 \\
\hline Relationships & Satisfaction with relationships with other people & 0.2447 \\
\hline Conditions & Satisfaction with living conditions & 0.1838 \\
\hline
\end{tabular}

Source: author's calculations. 
conditions (0.18), the highest is satisfaction with general health $(0.33)$ and self-satisfaction $(0.33)$.

The maximum value of the mental health indicator obtained in the sample is 16.41, the minimum is 1.52 .

\section{Model}

We shall take into account the fact that many respondents avoided the question on household income. As a proxy variable of income, we shall use the answer to the question of the second wave of the study (Q0002): "Do you have enough money to cover your daily needs?" (Money) (see Table 7).

Table 7. Description of additional variables.

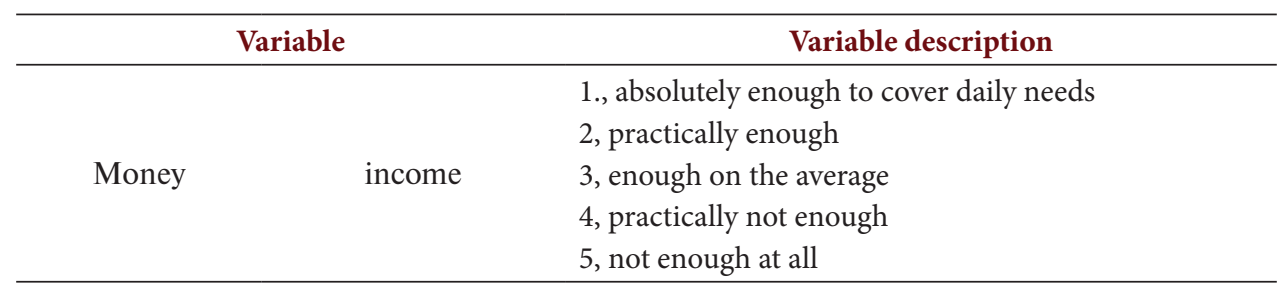

Source: WHO SAGE, 2007-2010.

Thus, the estimated model, which includes a variable reflecting the sufficiency of money to cover daily needs, instead of disposable household income, will take the form of:

\section{Basic specification}

Model 1.

$$
\begin{gathered}
\text { Mental_Health }_{t i}=\beta_{1}+\beta_{2}{ }^{*} \text { Sex }_{i}+\beta_{3} * \text { Age }_{t i}+\beta_{4} * \text { Married }_{t i}+ \\
+\beta_{5}{ }^{*} \text { Cohabiting }_{t i}+\beta_{6} * \text { Divorced }_{t i}+\beta_{7} * \text { Widowed }_{t i}+\beta_{8}{ }^{*} \text { Secondary }_{i}+ \\
+\beta_{9}{ }^{*} \text { University }_{i}+\beta_{10} * \text { PhD }_{i}+\beta_{11}{ }^{*} \text { Money }_{i}+\beta_{12} * \text { Health }_{t-1, i}+ \\
+\beta_{13}{ }^{*} \text { Generalized_Trust }_{t, i}+\beta_{14}{ }^{*} \text { Person_Needed_Care }_{t, i}+\varepsilon_{i}
\end{gathered}
$$

To get additional specifications, we construct models with less number of indicators (Model 3) and we will use the level of interpersonal trust instead of generalized trust (Model 2, "long" and Model 4 "short", as the indicators of interpersonal and intra-group levels of trust are strongly correlated).

\section{Model 2.}

$$
\begin{aligned}
& \text { Mental_Health }{ }_{t i}=\beta_{1}+\beta_{2}{ }^{*} \text { Sex }_{i}+\beta_{3}{ }^{*} \text { Age }_{t i}+\beta_{4}{ }^{*} \text { Married }_{t i}+ \\
& +\beta_{5}{ }^{*} \text { Cohabiting }_{t i}+\beta_{6} * \text { Divorced }_{t i}+\beta_{7} * \text { Widowed }_{t i}+\beta_{8} * \text { Secondary }_{i}+ \\
& +\beta_{9} * \text { University }_{i}+\beta_{10} * P h D_{i}+\beta_{11} * \text { Money }_{i}+\beta_{12} * \text { Health }_{t-1, i}+ \\
& +\beta_{13} * \text { Person_to_Trust } t_{t, i}+\beta_{14} * \text { Person_Needed_Care }{ }_{t, i}+\varepsilon_{i}
\end{aligned}
$$


Model 3.

$$
\begin{aligned}
& \text { Mental_Health }{ }_{t i}=\beta_{1}+\beta_{2} * \text { Sex }_{i}+\beta_{3}^{*} \text { Age }_{t i}+\beta_{4} * \text { Widowed }_{t i}+ \\
& +\beta_{5}{ }^{*} \text { University }_{i}+\beta_{6}{ }^{*} \text { PhD } D_{i}+\beta_{7}{ }^{*} \text { Money }_{i}+\beta_{8}{ }^{*} \text { Health }_{t-1, i}+ \\
& +\beta_{9}{ }^{*} \text { Generalized_Trust } t_{t, i}+\beta_{10} * \text { Person_Needed_Care }{ }_{t i}+\varepsilon_{i}
\end{aligned}
$$

Model 4.

$$
\begin{gathered}
\text { Mental_Health }_{t i}=\beta_{1}+\beta_{2} * \operatorname{Sex}_{i}+\beta_{3}^{*} \text { Age }_{t i}+\beta_{4} * \text { Widowed }_{t i}+ \\
+\beta_{5} * \text { University }_{i}+\beta_{6} * \text { PhD }_{i}+\beta_{7} * \text { Money }_{i}+\beta_{8}{ }^{*} \text { Health }_{t-1, i}+ \\
+\beta_{9} * \text { Person_to_Trust } \\
t, i
\end{gathered}
$$

\section{Results}

According to the achieved results, the most significant relationship with mental health comes from age, income and physical health of the respondent. The Hypothesis $\mathrm{H}_{1}$ is fully confirmed: all other things being equal, women in Russia are on average more susceptible to deterioration of mental health status.

On the basis of the set of approaches presented in the theoretical part of the article we can emphasize the importance of the emotional state of the respondent at the time of questioning. However, the time lag between the emotionally severe events and the time of survey are to be taken into consideration.

The Hypothesis $\mathrm{H}_{2}$ about negative correlation between the loss of a spouse and the state of the mental health of the respondent, is partly confirmed.

The suggestion about strong influence of the level of education (the Hypothesis $\mathrm{H}_{3}$ ) is not confirmed. Only the full higher education in the "long" specifications of the models is of importance.

The level of interpersonal trust and generalized level of trust do not differ in their impact on mental health, however, the presence of a close person is more closely related to a higher level of mental health of the elderly than the general level of trust in people. Therefore, the Hypothesis $\mathrm{H}_{4}$ ) is confirmed but with a note to different degree of the influence of the used characteristics.

With the increase in age, all other things being equal, on average, there is a deterioration in mental health (with the increase in age by 1 year, mental health deteriorates by 0.01 conventional units of measurement. Sufficiency in money, measured by the question of income adequacy to cover daily needs, suggests more stable mental health and well-being. Good physical health determines good mental health and well-being in the future.

\section{Subsampling of observations}

In dividing the totality of respondents into sub-samples by gender, the objective was to identify differences in factors related to mental health for men and women. It turns that for men, the greatest influence is the absence of a spouse (divorced or widowed status), contributing to 3.12 and 2.23 units respectively, which is significant in the five-point measurement of the dependent variable. In addition, there is a strong correlation between the mental health of 
men and the sufficiency of available money, the generalized level of trust and the presence of a close relative in need of the respondent's support (including emotional).

For women, unlike men, there is a significant correlation between the level of education and the level of mental health, namely, completed secondary education, among other things being equal, improves mental health and well-being of women by 0.5 on average (the result is similar in both models for a this sub-sample). In addition, the presence of a trustworthy person as well as a generalized level of trust are more important for women when compared to men. Both for women and men, physical health and sufficient money to cover daily needs are important factors for mental health and well-being. It is worth mentioning that the presence of a relative in need of support (including emotional support) has a larger negative impact on the level of mental health and well-being for women.

Mental and behavioral disorders deteriorate the quality of life of the respondent and his/her environment. Thus, by identifying the key socio-economic determinants of mental health and well-being of the elderly population of Russia and the main risk factors of mental health disorders, it is possible to elaborate the mechanisms, which would positively affect mental health and therefore, improve the quality of life of the elderly population As a result, it will contribute to increasing the life expectancy, on the one hand, and improving the social and economic well-being of society as a whole, on the other hand.

\section{Limitations}

It is necessary to note some limitations that need to be taken into account in further interpreting the calculations and the received correlations.

\section{Selection of the sample}

In such kind of studies, the selection effect is considered from several perspectives. First of all, it should be emphasized that health surveys often involve healthier people than the general health of the entire population. Secondly, some authors note a decrease in the prevalence of mental illness (depressive episodes) with an increase in the age of the individual; in other words, persons with a more stable mentality who are less susceptible to mental disorders survive to older ages (Bobak et al. 2006).

\section{Subjectivity of evaluations}

The SAGE study presents self-reported indicators of health, social activity and lifestyle. To measure the of health level we have to use proxy-variables. It can result in shifted assessment of the health state. Therefore, the use of subjective methods can result in over-estimation of the health state. However, in this case the shifted assessment does not affect the presence or absence of differences in mental health between particular socio-demographic groups of population.

\section{Comorbidity}

Comorbidity manifests itself in the difficulty of identifying certain mental (depressive) disorders due to the presence of multiple concomitant diseases in this age group. The elderly 
people usually have a set of chronic diseases (diabetes, asthma, bone and muscular diseases, etc.), which can also affect the state of mental health. Investigation of relationships between chronic diseases and mental health can be the development of this study.

\section{Conclusion}

This paper presents a method for assessing mental health and well-being of the elderly population of Russia and its testing on the data of the WHO Study on Global Ageing and Adult Health (SAGE). The implementation of the empirical strategy allowed to make conclusions about the close connection of mental health and well-being with the age of the respondent, sex, the sufficiency of money to cover daily needs, confidence, physical health, and stress.

The author agrees with the authoritative opinion of other researchers on the need for further research in order to better understand the existing links between socio-economic characteristics and mental health.

Application of the principal components analysis instead of aggregated index for calculation the mental health indicator allows to maximize the variance in the original data, reducing their dimensionality in an optimal way.

Despite the fact that the concept of mental health and well-being at present has not yet found proper representation in the works of Russian researchers, the author suggests that this issue will become one of the most relevant in the near future, because the problems of mental health and well-being under the conditions of population ageing are problems of a global level.

\section{Reference list}

Averina M, Nilssen O, Brenn T, Brox J, Arkhipovsky VL, Kalinin AG (2005) Social and lifestyle determinants of depression, anxiety, sleeping disorders and self-evaluated quality of life in Russia: a population-based study in Arkhangelsk. Social Psychiatry and Psychiatric Epidemiology. 40(7): 511-518.

Bertrand M, Sendhil M (2001) Do People Mean What They Say? Implications for Subjective Survey Data. American Economic Review 91(2): 67-72.

Bobak M, Pikhart H, Pajak A, Kubinova R, Malyutina S, Sebakova H, Topor-Madry R, Nikitin Y, Marmot M (2006) Depressive symptoms in urban population samples in Russia, Poland and the Czech Republic. British Journal of Psychiatry 188: 359-365.

Bound J (1991) Self-Reported Versus Objective Measures of Health in Retirement Models. The Journal of Human Resources 26(1): 106-138.

Bradburn NM (1969) The structure of psychological well-being. Aldine, Chicago.

Charman T, Pervova I (1996) Self-Reported Depressed Mood in Russian and U. K. Schoolchildren. Journal of Child Psychology and Psychiatry 37(7): 879-883.

Cooke PJ, Melchert TP, Connor K (2016) Measuring well-being: A review of instruments. The Counseling Psychologist 44(5): 730-757.

Danilova I (2014) Smertnost' pozhilyh ot vneshnih prichin v Rossii [Mortality of the elderly from external causes in Russia]. Demographic Review [Demograficheskoe obozrenie]. 1(2): 57-84. (in Russian)

Diener E (1984) Subjective well-being. Psychological Bulletin 95: 542-575. 
Diener ED, Emmons RA, Larsen RJ, Griffin S (1985) The Satisfaction With Life Scale. Journal of Personality Assessment 49(1): 71-75.

Diener E, Suh EM, Lucas RE, Smith HL (1999) Subjective well-being: three decades of progress. Psychological Bulletin 125: 276-302.

Fox PJ, Kohatsu N, Max W, Arnsberger P (2001) Estimating the costs of caring for people with Alzheimer disease in California: 2000-2040. Journal of Public Health Policy 22(1): 88-97.

Friedli L (2009) Mental health, resilience and inequalities. WHO Regional Office for Europe, Copenhagen.

Gurin G, Veroff J, Feld S (1960) Americans view their mental health. Basic Books, New York.

Gurovich IYa, Lyubov EB, Chapurin SA, Churilin Yu, Yenaliev IR (2010) Bremja depressivnyh rasstrojstv v otechestvennyh psihiatricheskih sluzhbah. [The burden of depressive disorders in the Russian psychiatric services]. Zhurnal nevrologii i psihiatrii [Journal of Neurology and Psychiatry] 3: $77-$ 82. (in Russian)

Jogerst JJ, Frolova EV, Dubikaitis TA (2010) Depressija v pozdnem periode zhizni: predstavlenija o zabolevanii pozhilyh zhitelej Sankt-Peterburga [Depression in the late period of life: perceptions of the disease of elderly residents of St.Petersburg]. Uspehi gerontologii [Successes of Gerontology] 23(2): 249-256. (in Russian)

Jose PE, D’Anna CA, Cafasso LL, Bryant FB (1998) Stress and Coping Among Russian and American Early Adolescents. Developmental Psychology 34(4): 757-769.

Joseph S, Linley PA (2004) Positive therapy: A positive psychological theory of therapeutic practice. In: Linley PA, Joseph S (Eds.) Positive psychology in practice. Wiley, Hoboken, NJ, 354 -368.

Hoch JS, Briggs AH, Willan AR (2002) Something old, something new, something borrowed, something blue: a framework for the marriage of health econometrics and cost-effectiveness analysis. Health Economics 11: 415-430.

Ivanets NN, Kinkulkina MA, Avdeeva TI, Izyumina TA (2016) Izuchenie vozmozhnostej primenenija standartizirovannyh shkal samoocenki trevogi i depressii pri obsledovanii bol'nyh pozhilogo vozrasta: shkaly-oprosniki depressii [Study of the possibilities of using standardized scales of self-assessment of anxiety and depression in the examination of elderly patients: depression scale surveys]. Zhurnal nevrologii i psihiatrii [Journal of Neurology and Psychiatry] 10: 51-59. (in Russian)

Kennedy BP, Kawachi I, Brainerd E (1998) The role of social capital in the Russian mortality crisis. World Development 26(11): 2029-2043.

Keyes CLM (1998) Social well-being. Social Psychology Quarterly 61: 121-140.

Keyes CLM, Shmotkin D, Ryff CD (2002) Optimizing well-being: The empirical encounter of two traditions. Journal of Personality and Social Psychology 82: 1007-1022.

Lindeboom M, Portrait F, van den Berg GJ (2002) An econometric analysis of the mental-health effects of major events in the life of older individuals. Health Economics 11: 505-520.

Lovibond SH, Lovibond PF (1995) Manual for the Depression Anxiety \& Stress Scales. (2nd ed.). Psychology Foundation, Sydney.

Lyubomirsky S, Lepper H (1999) A measure of subjective happiness: Preliminary reliability and construct validation. Social Indicators Research 46: 137-155.

Lyubov EB, Yastrebov VS (2012) Jekonomicheskoe bremja shizofrenii v Rossii [Economic burden of schizophrenia in Russia]. Social'naja i klinicheskaja psihiatrija [Social and clinical psychiatry] 3: 36-42. (in Russian)

Murray CJL, Lopez AD (Eds.) (1996) The global burden of disease: A comprehensive assessment of mortality and disability from diseases, injuries, and risk factors in 1990 and projected to 2020. Harvard School of Public Health, Cambridge. 
Nicholson A, Pikhart H, Pajak A, Malyutina S, Kubinova R, Peasey A, et al. (2008) Socioeconomic status over the life-course and depressive symptoms in men and women in Eastern Europe. Journal of Affective Disorders 105: 125-136.

Nilssen O, Brenn T, Hwyer G, Lipton R, Boiko J, Tkachev A (1999) Self-reported seasonal variation in depression at 78 degree North: The Svalbard Study. International Journal of Circumpolar Health 58: $14-23$.

Oksuzyan A, Shkolnikova M, Vaupel JW, Christensen K, Shkolnikov VM (2015) Sex Differences in Biological Markers of Health in the Study of Stress, Aging and Health in Russia. PLOS ONE 10(6): e0131691.

Oliva-Moreno J, Lopez-Bastida J, Montejo-Gonzalez AL, Osuna-Guerrero R, Duque-Gonzalez B (2009) The socioeconomic costs of mental illness in Spain. European Journal of Health Economics 10: 361-369.

Pakriev S, Vasar V, Aluoja A, Saarma M, Shlik J (1998) Prevalence of mood disorders in the rural population of Udmurtia. Acta Psychiatrica Scandinavica 97: 169-174.

Raab M, Fasang AE, Hess M (2018) Pathways to death: The co-occurrence of physical and mental health in the last years of life. Demographic Research 38: 1619-1634.

Radloff LS (1977) The CES-D Scale: A self-report depression scale for research in the general population. Applied Psychological Measurement 1: 385-401.

Roberts RE, Kaplan GA, Shema SJ, Strawbridge WJ (1997) Does Growing Old Increase the Risk for Depression? The American Journal of Psychiatry 154(10): 1384-1390.

Rose R (2000) How much does social capital add to individual health? A survey study of Russians. Social Science \& Medicine 51(9): 1421-1435.

Rusinova NL, Safronov VV (2017) Personal'nye psihologicheskie resursy i social'nye neravenstva v zdorov'e: vyrazhennost' bufernogo jeffekta v evropejskih stranah [Personal psychological resources and social inequalities in health: exposure of the buffer effect in European countries]. Demograficheskoe obozrenie [Demographic Review] 3: 59-87. (in Russian)

Ryff CD (1989) Happiness is everything, or is it? Explorations on the meaning of psychological well-being. Journal of Personality and Social Psychology 57: 1069-1081.

Shkolnikova M, Shalnova S, Shkolnikov VM, Metelskaya V, Deev A, Andreev E, Jdanov D, Vaupel JW (2009) Biological mechanisms of disease and death in Moscow: rationale and design of the survey on Stress Aging and Health in Russia (SAHR). BMC Public Health 9: doi: 10.1186/1471-2458-9-293

Sigerist HE (1941) Medicine and human welfare. Yale University Press, New Haven.

Stewart-Brown S (2002) Measuring parts most measures do not reach: a necessity for evaluation in mental health promotion. International Journal of Mental Health Promotion 1: 4-9.

Sullivan PF, Daly MJ, O’Donovan M (2012) Genetic architecture of psychiatric disorders: the emerging picture and its implications. Nature Reviews Genetics 13: 537-551.

Urbanos-Garrido RM, Lopez-Valcarcel BG (2015) The influence of the economic crisis on the association between unemployment and health: an empirical analysis for Spain. European Journal of Health Economics 16: 175-184.

Vishnevsky AG (ed.) (2017) Smertnost' ot vneshnih prichin v Rossii s serediny XX veka. [Mortality from external causes in Russia since the mid-20th century] Publishing House of the Higher School of Economics, Moscow. 448 p. (in Russian)

Watson D, Clark LA, Tellegen A (1988). Development and validation of brief measures of positive and negative affect: The PANAS Scales. Journal of Personality and Social Psychology 47: 1063-1070.

Weich S, Patterson J, Shaw R, Stewart-Brown S (2009) Family relationships in childhood and common psychiatric disorders in later life: Systematic review of prospective studies. British Journal of Psychiatry 194(5): 392-398. 
Weiden PJ, Olfson M (1995) Cost of relapse in schizophrenia. Schizophrenia Bulletin 21(3): 421-429. Westlund K, Søgaard AJ (1993) Helse, livsstil og levekår i Finnmark. Resultater fra hjertekarundersøkelsen i 1987-88 [Health, life style and living conditions in Finnmark. Results from Cardiovascular study in 1987-1988]. Institute of Community Medicine press, Tromsø (in Norwegian)

Wubker A, Zwakhalen S, Challis D, Suhonen R, Karlsson S, Zabalegui A, Soto M, Saks K, Sauerland D (2015) Costs of care for people with dementia just before and after nursing home placement: primary data from eight European countries. European Journal of Health Economics 16: 689-707.

World Health Organization (1948) World Health Organization Constitution. Geneva.

World Health Organization (2004) Promoting mental health: concepts, emerging evidence, practice: Summary report. Geneva.

World Health Organization (2017) Mental health atlas. Geneva.

\section{Information about the author}

- Anna Mikhailovna Kashcheeva, Analyst of the "Finance" Department of the "Technologies” Section in the PJSC Sberbank. E-mail: kashcheeva.msu@gmail.com 


\section{Appendix}

Table A. Results. Full sample models.

\begin{tabular}{|c|c|c|c|c|c|c|c|c|}
\hline \multicolumn{9}{|c|}{ Dependent variable: Mental Health (PCA) } \\
\hline & \multicolumn{2}{|l|}{ Model 1} & \multicolumn{2}{|l|}{ Model 2} & \multicolumn{2}{|l|}{ Model 3} & \multicolumn{2}{|c|}{ Model 4} \\
\hline \multirow{2}{*}{ const } & 0.5242 & & 0.4706 & & 0.8375 & & 0.9995 & \\
\hline & $(0,823)$ & & $(0,8462)$ & & $(0,6816)$ & & $(0,7138)$ & \\
\hline \multirow{2}{*}{ Sex } & 0.0584 & * & 0.4212 & * & 0.3934 & * & 0.4281 & * \\
\hline & $(0,01)$ & & $(0,2247)$ & & $(0,2151)$ & & $(0,2189)$ & \\
\hline \multirow{2}{*}{ Age } & 0.3819 & $* * *$ & 0.0586 & $* * *$ & 0.055 & $* * *$ & 0.0549 & $* * *$ \\
\hline & $(0,2208)$ & & $(0,0101)$ & & $(0,0097)$ & & $(0,0098)$ & \\
\hline \multirow{2}{*}{ Married } & 0.1721 & & 0.3744 & & & & & \\
\hline & $(0,4274)$ & & $(0,4235)$ & & & & & \\
\hline \multirow{2}{*}{ Cohabiting } & 0.2697 & & 0.7307 & & & & & \\
\hline & $(0,5586)$ & & $(0,562)$ & & & & & \\
\hline \multirow{2}{*}{ Divorced } & 0.3401 & & 0.5033 & & & & & \\
\hline & $(0,493)$ & & $(0,4872)$ & & & & & \\
\hline \multirow{2}{*}{ Widowed } & 0.3358 & & 0.5404 & & 0.1317 & & 0.1573 & \\
\hline & $(0,4215)$ & & $(0,4142)$ & & $(0,1798)$ & & $(0,1846)$ & \\
\hline \multirow{2}{*}{ Secondary } & -0.4335 & $* *$ & -0.4451 & $* *$ & & & & \\
\hline & $(0,1889)$ & & $(0,1884)$ & & & & & \\
\hline \multirow{2}{*}{ University } & 0.2203 & & 0.1865 & & 0.3234 & * & 0.3013 & \\
\hline & $(0,1846)$ & & $(0,1874)$ & & $(0,1816)$ & & $(0,1847)$ & \\
\hline \multirow{2}{*}{$\mathrm{PhD}$} & 0.0293 & & -0.0313 & & 0.1397 & & 0.1036 & \\
\hline & $(0,4002)$ & & $(0,4157)$ & & $(0,3985)$ & & $(0,4216)$ & \\
\hline \multirow{2}{*}{ Money } & 0.406 & $* * *$ & 0.3894 & $* * *$ & 0.4023 & $* * *$ & 0.3826 & $* * *$ \\
\hline & $(0,0748)$ & & $(0,0755)$ & & $(0,075)$ & & $(0,0759)$ & \\
\hline \multirow{2}{*}{ Health } & 0.4863 & $* * *$ & 0.5199 & $* * *$ & 0.4849 & $* * *$ & 0.5112 & $* * *$ \\
\hline & $(0,1194)$ & & $(0,1195)$ & & $(0,1202)$ & & $(0,1205)$ & \\
\hline \multirow{2}{*}{ Generalized Trust } & -0.478 & $* * *$ & & & -0.4814 & $* * *$ & & \\
\hline & $(0,183)$ & & & & $(0,1827)$ & & & \\
\hline \multirow{2}{*}{ Person to Trust } & & & -0.4583 & $* *$ & & & -0.4361 & \\
\hline & & & $(0,1967)$ & & & & $(0,1947)$ & \\
\hline \multirow{2}{*}{ Person needed care } & 0.1735 & $* * *$ & 0.6654 & $* *$ & 0.1699 & $* * *$ & 0.6638 & $* *$ \\
\hline & $(0,0315)$ & & $(0,2735)$ & & $(0,03)$ & & $(0,2737)$ & \\
\hline R-squared & 0.2307 & & 0.2322 & & 0.2217 & & 0.2211 & \\
\hline adj. R-squared & 0.2122 & & 0.2137 & & 0.2094 & & 0.2086 & \\
\hline $\mathbf{F}$ & 13.26 & & 13.28 & & 19.77 & & 20.03 & \\
\hline $\mathbf{P}$ & 0 & & 0 & & 0 & & 0 & \\
\hline Log-likelihood & $-1019,06$ & & -1016.70 & & -1022.22 & & -1020.3 & \\
\hline AIC & 2064.11 & & 2059.41 & & 2062.04 & & 2058.7 & \\
\hline BIC & 2119.23 & & 2114.48 & & 2100.20 & & 2096.9 & \\
\hline $\mathbf{N}$ & 513 & & 511 & & 513 & & 511 & \\
\hline
\end{tabular}

Source: author's calculations 


\section{Ramsey Test}

The Ramsey test proves that the model specification is correct. All constructed models are correctly specified, but at different levels of significance. The most reliable models for interpretation are Model 1 and Model 3.

The results of the Ramsey test are presented in Table B.

Table B. Ramsey Test Results for Full Sample Models (1)-(4).

\begin{tabular}{ll}
\hline Model 1 & p-value $=$ P $(\mathrm{F}(2.497)>0.58628)=0.853$ \\
\hline Model 2 & p-value $=$ P $(\mathrm{F}(2.495)>0.84713)=0.429$ \\
\hline Model 3 & p-value $=$ P $(\mathrm{F}(2.502)>0.318008)=0.728$ \\
\hline Model 4 & p-value $=$ P $(\mathrm{F}(2.500)>2.31234)=0.1$ \\
\hline
\end{tabular}

Source: author's calculations.

\section{Wald Test}

The Wald test enables comparing "short" and "long" regressions. So we can compare models 1,3 and models 2, 4. In both cases, the test shows the correctness of the choice of a longer regression, which is correlated with the results of the Ramsey test.

The results of the Wald test are presented in Table C.

Table C. Wald Test Results for Full Sample Models (1)-(4).

\begin{tabular}{ll}
\hline \multirow{2}{*}{ Models 1,3 } & Test statistics: TR^2 $=73,481884$, \\
& p-value $=\mathrm{P}($ Chi-square $(31)>73,481884)=0.000026$ \\
\hline \multirow{2}{*}{ Models 2, 4 } & Test statistics: TR^2 $=102,650918$, \\
& p-value $=\mathrm{P}($ Chi-square $(57)>102,650918)=0.000200$ \\
\hline
\end{tabular}

Source: author's calculations.

Using the advantage of individual data, we divide the initial sample into two sub-samples by gender - a sub-sample of males ("M") and a sub-sample of females ("F") of retirement ages.

Table D presents the model evaluation results for sub-sample "M"; and Table E for sub-sample "F". 
Table D. Results. Sub-sample "M".

Dependent variable: Mental Health (PCA)

\begin{tabular}{|c|c|c|c|c|}
\hline & \multicolumn{2}{|c|}{ Model 1} & \multicolumn{2}{|c|}{ Model 2} \\
\hline \multirow{2}{*}{ const } & 1.6786 & & 1.6594 & \\
\hline & $(2,1399)$ & & $(2,244)$ & \\
\hline \multirow{2}{*}{ Age } & 0.0206 & & 0.0132 & \\
\hline & $(0,0288)$ & & $(0,0308)$ & \\
\hline \multirow{2}{*}{ Married } & 2.3398 & & 2.5236 & \\
\hline & $(0,5669)$ & & $(0,5952)$ & \\
\hline \multirow{2}{*}{ Cohabiting } & 1.0626 & & 1.2033 & \\
\hline & $(0,6417)$ & & $(0,7236)$ & \\
\hline \multirow{2}{*}{ Divorced } & 3.1247 & $* * *$ & 3.349 & $* * *$ \\
\hline & $(1,0154)$ & & $(1,0252)$ & \\
\hline \multirow{2}{*}{ Widowed } & 2.227 & *** & 2.3689 & $* * *$ \\
\hline & $(0,5424)$ & & $(0,5798)$ & \\
\hline \multirow{2}{*}{ Secondary } & -0.3609 & & -0.3718 & \\
\hline & $(0,4304)$ & & $(0,4259)$ & \\
\hline \multirow{2}{*}{ University } & 0.7208 & & 0.6986 & \\
\hline & $(0,4369)$ & & $(0,4365)$ & \\
\hline \multirow{2}{*}{ PhD } & -0.0138 & & 0.0002 & \\
\hline & $(1,2756)$ & & $(1,39)$ & \\
\hline \multirow{2}{*}{ Money } & 0.3095 & * & 0.3 & * \\
\hline & $(0,1641)$ & & $(0,1723)$ & \\
\hline \multirow{2}{*}{ Health } & 0.3331 & & 0.4799 & \\
\hline & $(0,3165)$ & & $(0,3408)$ & \\
\hline \multirow{2}{*}{ Generalized Trust } & -0.6923 & $*$ & & \\
\hline & $(0,3636)$ & & & \\
\hline \multirow{2}{*}{ Person to Trust } & & & -0.3312 & \\
\hline & & & $(0,4772)$ & \\
\hline \multirow{2}{*}{ Person needed care } & 1.4063 & $* *$ & 1.3401 & * \\
\hline & $(0,7014)$ & & $(0,6981)$ & \\
\hline
\end{tabular}

\begin{tabular}{lcc}
\hline R-squared & 0.1794 & 0.1617 \\
\hline adj. R-squared & 0.0819 & 0.0611 \\
\hline F & 8.2508 & 562683 \\
\hline $\mathbf{P}$ & 0 & 0 \\
\hline Log-likelihood & -228.9312 & -228.6191 \\
\hline AIC & 483.8624 & 483.2381 \\
\hline BIC & 519.43 & 518.69 \\
\hline $\mathbf{N}$ & 114 & 113 \\
\hline
\end{tabular}

Source: author's calculations. 
Table E. Results. Sub-sample "F".

\begin{tabular}{|c|c|c|c|c|}
\hline \multicolumn{5}{|c|}{ Dependent variable: Mental Health (PCA) } \\
\hline & \multicolumn{2}{|c|}{ Model 1} & \multicolumn{2}{|c|}{ Model 2} \\
\hline \multirow{2}{*}{ const } & 0.5278 & & 0.6503 & \\
\hline & $(0,8068)$ & & $(0,8229)$ & \\
\hline \multirow{2}{*}{ Age } & 0.0653 & $* * *$ & 0.0661 & $\forall * *$ \\
\hline & $(0,0104)$ & & $(0,0104)$ & \\
\hline \multirow{2}{*}{ Married } & -0.1014 & & 0.1031 & \\
\hline & $(0,4572)$ & & $(0,4463)$ & \\
\hline \multirow{2}{*}{ Cohabiting } & 0.3707 & & 0.8504 & \\
\hline & $(0,6051)$ & & $(0,5906)$ & \\
\hline \multirow{2}{*}{ Divorced } & 0.0647 & & 0.2173 & \\
\hline & $(0,5206)$ & & $(0,509)$ & \\
\hline \multirow{2}{*}{ Widowed } & 0.13 & & 0.351 & \\
\hline & $(0,4468)$ & & $(0,4312)$ & \\
\hline \multirow{2}{*}{ Secondary } & $-0,5353$ & $* *$ & -0.544 & $* * *$ \\
\hline & $(0,2076)$ & 等 & $(0,2047)$ & 等 \\
\hline \multirow{2}{*}{ University } & 0.0827 & & 0.0546 & \\
\hline & $(0,2038)$ & & $(0,2058)$ & \\
\hline \multirow{2}{*}{ PhD } & 0.1324 & & 0.1016 & \\
\hline & $(0,3175)$ & & $(0,3056)$ & \\
\hline \multirow{2}{*}{ Money } & 0.4301 & $* * *$ & 0.404 & $* * *$ \\
\hline & $(0,8387)$ & & $(0,0842)$ & \\
\hline \multirow{2}{*}{ Health } & 0.5127 & $* * *$ & 0.5226 & $* * *$ \\
\hline & $(0,1228)$ & . & $(0,1215)$ & 年 \\
\hline \multirow{2}{*}{ Generalized Trust } & -0.3874 & $\star$ & & \\
\hline & $(0,2082)$ & . & & \\
\hline \multirow{2}{*}{ Person to Trust } & & & -0.5502 & $* *$ \\
\hline & & & $(0,2162)$ & \\
\hline \multirow{2}{*}{ Person needed care } & 0.645 & ** & 0.6535 & $* *$ \\
\hline & $(286)$ & 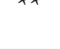 & $(2868)$ & \\
\hline R-squared & 0.2822 & & & \\
\hline adj. R-squared & 0.2618 & & & \\
\hline $\mathbf{F}$ & 14.3596 & & & \\
\hline $\mathbf{P}$ & 0 & & & \\
\hline Log-likelihood & -778.62 & & & \\
\hline AIC & 1581.24 & & & \\
\hline BIC & 1629.11 & & & \\
\hline $\mathbf{N}$ & 399 & & & \\
\hline
\end{tabular}

Source: author's calculations. 
Similar to the previous models, the Ramsey test was applied (see Table F, G).

The models constructed for corresponding sub-samples of males and females are correctly specified. However, the most reliable results are shown by models that include a generalized rather than interpersonal level of trust.

Table F. Ramsey Test Results for Models (1)-(2) for sub-sample "M".

\begin{tabular}{ll}
\hline Model 1 & p-value $=\mathrm{P}(\mathrm{F}(2.99)>0.0463085)=0.955$ \\
\hline Model 2 & p-value $=\mathrm{P}(\mathrm{F}(2.98)>0.175306)=0.839$ \\
\hline
\end{tabular}

Source: author's calculations.

Table G. Ramsey Test Results for Models (1)-(2) for sub-sample "F".

\begin{tabular}{ll}
\hline Model 1 & p-value $=\mathrm{P}(\mathrm{F}(2.385)>0.0766401)=0.926$ \\
\hline Model 2 & p-value $=\mathrm{P}(\mathrm{F}(2.384)>1.31087)=0.271$ \\
\hline
\end{tabular}

Source: author's calculations. 